\title{
The Consequences of Population Growth on the Demographic Characteristics of Abu Dhabi City in the United Arab Emirates
}

\author{
Fayez M. Elessawy \\ Department of Geography and Urban Sustainability, United Arab Emirates University, United Arab Emirates
}

Received May 7, 2020; Revised June 9, 2020; Accepted July 7, 2020

Copyright $\bigcirc 2020$ by authors, all rights reserved. Authors agree that this article remains permanently open access under the terms of the Creative Commons Attribution License 4.0 International License

\begin{abstract}
Abu Dhabi is the capital of the United Arab Emirates. Abu Dhabi and other Arabian Gulf cities have developed rapidly in the second half of 20th century, due to the increase of oil and gas revenues. The total population of the city has grown by $1000 \%$ over the last 42 years; according to the first census in 1975, the total population was 120,000 , which increased in 2018 to more than 1.25 million, with annual growth rate more than $5.7 \%$. This increase makes Abu Dhabi's population be one of the fastest-growing urban centres in the world. The current population increase, resulted from remarkable declining of birth rates and increasing flow of-immigrants, rises from only 87 thousand in 1975 to half-million in 2005. The immigrant flow has doubled-to-more than one million in 2018. The non-national proportion increased continuously from $72 \%$ in 1975 to nearly $90 \%$ of the total population of the city in 2018. Most of them are Asians. These figures reflect the enormity of the growing role of non-national workers in the population growth of the city over the last four decades. Besides, the increased number of foreigners is creating many positive and negative impacts on Emirati society. This study investigates some effects on the demographic characteristics of Emirati society, particularly, on creating an imbalance of age and sex ratios and unique composition of labour force. The researcher applied the topical approach including analytical and cartographic techniques to reach the study aims.
\end{abstract}

Keywords Abu Dhabi Population Growth, Guest Workers, Asians, Unbalanced Age-sex Structure, Labour Force

\section{Introduction}

Abu Dhabi and other Arabian Gulf urban canters have developed rapidly in the second half of 20th century, due to the increase-of oil and gas revenues. The fast economic growth resulted in-urbanization, with the establishment of the United Arab Emirates in 1971 and Abu Dhabi as capital, the country has received large numbers of immigrant workers whose advent has dramatically changed the geography. The need for immigrant workers was coincided with the economic boom, which resulted from immense oil revenues. The government invested in colossal Projects, which aimed at building the country's infrastructure. Abu Dhabi and other large urban centres witnessed a great boom in population and in urban development.

The size of the population of Abu Dhabi city was very small before 1975. The majority of population were citizens engaged in fishing and trade activities. The total population has grown by nearly $1000 \%$ over the last 40 years, whereas in 1975 the total population was 110,000 , increased to more than 1.25 million in 2018. This increase makes Abu Dhabi population be one of the fastest growing cities in the world. In a related context, guest workers (immigrants) have profoundly contributed to this population growth since they constituted about $90 \%$ of the total population. The guest workers came from many different countries but mostly from Asia and the Arab. Asians,-constituted at least $65 \%$ of the total population. The immigrant population also contained small percentage of European and Americans. Apparently, the foreign labourers were engaged in all fields of works. Furthermore, they played a very significant role in the development of the city.

Abu Dhabi city is a good example of a rapidly developing city. From 1975 to present the urban area has expanded enormously. The rapid development of the city transforms Abu Dhabi from a small city into a global business, financial and leisure hub. During the last two decades, Abu Dhabi city's built-up area expanded like never before, the economic growth accelerated and so did 
the investment level. More development projects were planned to support the urban sprawl of the city to change deserts into modern buildings and developed land use. The total built-up area increased from only 34 square Kilometres in 1975 to 761 square kilometres in 2017, as Abu Dhabi's area increased (1700\% in only 42 years). That high percentage makes the city one of the fastest-growing cities in the world. In brief, Abu Dhabi has undergone significant urban changes and great population growth over the past decades-which transformed it from a small desert trading centre to a global business hub and an economic centre.

The main target of the study is to show how Abu Dhabi's population increased to make the city one of the most populous cities in the United Arab Emirates. The researcher applied the topical an ach including analytical and cartographic techniques to reach the study aims: The Consequences of Population Growth on the Demographic Characteristics.

\section{Population Growth of Abu Dhabi City}

UAE Lack of clarity and scarcity of data-prior to 1975 , most of data depend on estimations. The initial accurate population census was obtained in 1975 , which represented the first demonstrative census, additional ones were performed later during the 80 's and 90 's and the latest one was the 2005 census. (Elessawy, F. (2014). Based on the different observations of the statistic figures and derivations, it was clear that until 1950's, the population of Abu Dhabi was small and personal trade, basic professions, as well as fishing and pearl collecting were sources of income. During the same period, the role of immigrant workers started to appear; for that reason, this period was described as the stage of "Slow Growth". An estimation of population size between 1930 and 1960 showed a double increase rom about 20,000 to 40,000. Table 1 below shows the population size of Abu Dhabi city between 1975 and 2018.
Table 1. Population Growth of Abu Dhabi city (1960 -2018)*

\begin{tabular}{|c|c|c|}
\hline Year & $\begin{array}{c}\text { Population Number 1000 } \\
\text { persons }\end{array}$ & $\begin{array}{c}\text { Annual Growth } \\
\text { Rate (\%) }\end{array}$ \\
\hline 2018 & 1,252 & 5.7 \\
\hline 2015 & 1,145 & 5.4 \\
\hline 2010 & 879 & 6.1 \\
\hline 2005 & 655 & 5.3 \\
\hline 2000 & 505 & 5.2 \\
\hline 1995 & 392 & 3.5 \\
\hline 1990 & 331 & 3.5 \\
\hline 1985 & 279 & 4.1 \\
\hline 1980 & 229 & 13.8 \\
\hline 1975 & 120 & 14.1 \\
\hline 1970 & 62 & 14.1 \\
\hline 1965 & 32 & 14.8 \\
\hline 1960 & 16 & ---- \\
\hline
\end{tabular}

*Source: Computed by the researcher according to censuses and estimations data from Ministries of Planning and Economy, UAE

Following the economic and social development during the past decades, exceptional population growth has been noticed. After the discovery and the increase in oil prices, the government of Abu Dhabi has been wealthy which motivated the building of an advanced infrastructure and money investors around the world were attracted to invest in Dubai Emirate. Economic policies of tax-free investments were considered as the attractive reasons. Consequently, many guest workers were needed to meet the need of the infrastructure and construction projects development since natives were not skilled enough for the required projects. Moreover, most of the foreign labour force was Asians.

The high oil revenues led to huge investments, which resulted in a fast increase in population, almost $1000 \%$ within 40 years from 1975 to 2018. Abu Dhabi's population increased from 120,000 in 1975 to 1.25 million in 2018. This period was described as the "Population Explosion Stage". The annual rate of population growth is $6 \%$, which indicates that the population may double in only 12 years, reaching a period that may be described as the Population Growth's Boom Stage. 


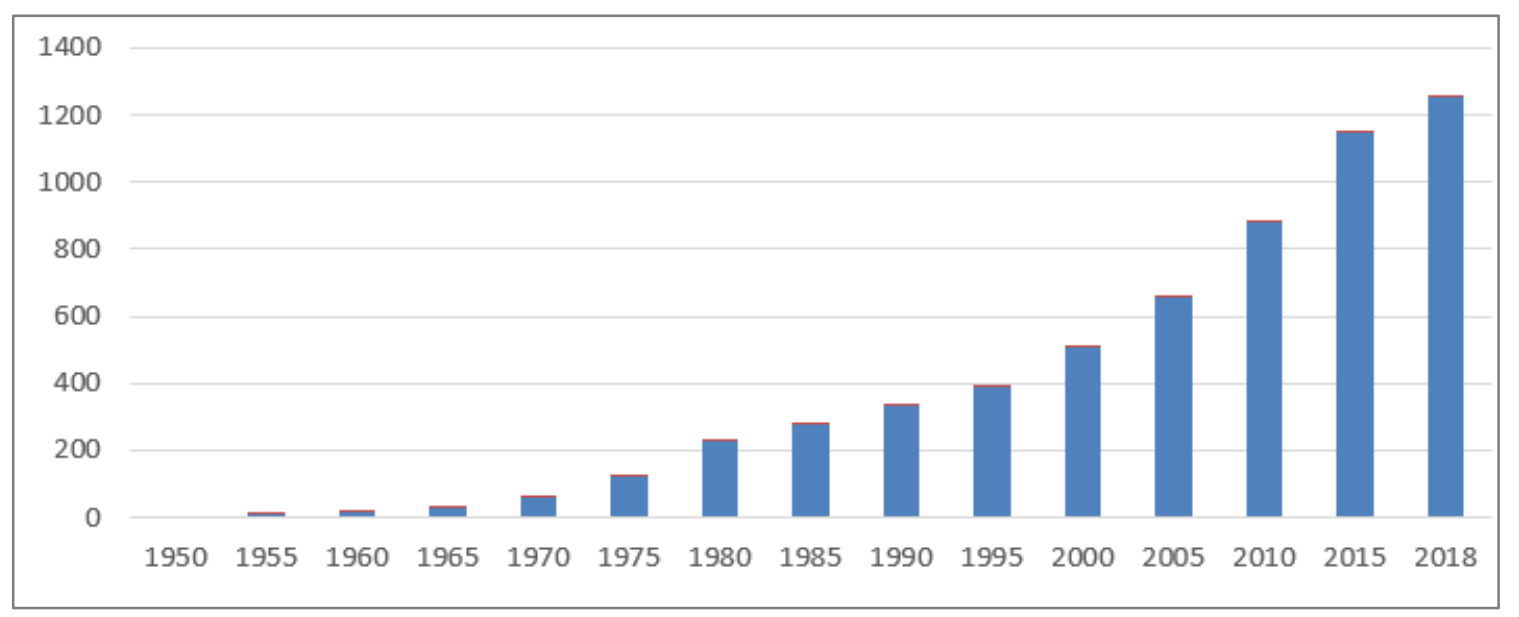

Figure 1. Population Growth of Abu Dhabi City from 1955-2018.

Although Abu Dhabi city ranked one of the highest rates of population growth among world cities, the influencing factor of this growth is still vague. Is it because of natural increase or immigration? To answer these questions, studying and investigating the components of the population growth, the natural increase and immigration, should be conducted.

The increase of population rate in Abu Dhabi was not considered as a natural increase. According to the statistics in table 2 below, a decline in natural increase from 26.2 to 12.1 per thousand between 1985 to 2015 . The increase in population basically is caused by the increase of immigrants, which represented about $80 \%$ of the population of the city in 2015 .

Table 2. Birth and Death Rates and Natural increase in Abu Dhabi city in Selected Years from 1985 - 2015 (figures per thousand)*

\begin{tabular}{|c|c|c|c|}
\hline Year & Birth & Death & Natural increase \\
\hline 1985 & 31.8 & 2.9 & 28.9 \\
\hline 1990 & 26.6 & 2.0 & 24.6 \\
\hline 1995 & 23.0 & 2.0 & 21.0 \\
\hline 2000 & 19.9 & 1.6 & 18.3 \\
\hline 2005 & 17.2 & 1.5 & 15.7 \\
\hline 2015 & 13.9 & 1.07 & 12.8 \\
\hline
\end{tabular}

*Source: Abu Dhabi Statistic Centre, 2015 Population and Vital Statists.

Table 2 and Figure 1 above, indicate that the death rate has declined to about 1.0 per thousand representing the lowest death rate worldwide, due to many reasons: population mainly consisting of adults (19 - 60 years old), economic and social progress, the improved quality of living, as well as, the enhancement in healthcare and education among the-public, at the same time the declining birth rate from 32 to 14 per thousand during the past 30 years. There is a clear difference in birth rates between the local and foreigners. Data show that rate of the local is 34 per thousand compared to only 17.2 for the non-citizen. However, the differences in death rates is not the same.
In summary, natural increase rates declined from approximately 29 to 13 per thousand during the last three decades, which means it has a low impact on population growth in Abu Dhabi in comparison to the immigration flow. Guest workers have affected the demographics of the country. Natural increase leads to a rise of newly born nationals of certain group of age or a decline as a result of the death of specific group of age such that both cases occur once in the lifetime of an individual. However, the majority of immigrants represent middle-aged men who join the labour force and have an effective role in the development of the UAE's economics and the demographic characteristics.

Table (3) shows the enormity of the growth in non-national workers over the last four decades. They increased from about 87 thousand in 1975 up to one 331 thousand in 1995, and during the following ten years reached 574 thousand in 2005. The immigrant flow has doubled in 10 years to reach more than one million in 2015.The percentage of non-national increased continuously from $72 \%$ in 1975 to nearly $90 \%$ of the total population of the city. The increase of the non-national citizens mostly in young men led to clear demographic, economic, cultural and social features, so the effect of foreign immigration with great numbers to the city has left a noticeable unbalanced population composition.

Table 3. The Increasing Number and Percentage of Non-National Population in Abu Dhabi from (1975-2015)*

\begin{tabular}{|c|c|c|}
\hline Years & Number of Non-National & \% of the Total Population \\
\hline 1975 & 86760 & 72.3 \\
\hline 1980 & 177246 & 77.4 \\
\hline 1985 & 215946 & 79.3 \\
\hline 1995 & 330848 & 84.4 \\
\hline 2005 & 573780 & 87.6 \\
\hline 2015 & 1024775 & 89.5 \\
\hline
\end{tabular}

*Source: Computed from different Censuses of Abu Dhabi city.

The majority of foreigners in Abu Dhabi are male 
although the number of women has also grown during the previous few decades of housekeepers and especially from Philippines. Indonesia, Bangladesh and Nepal. Most of foreigner men are hired in service sectors of low-skilled requirements, while women are mainly employed in jobs that are related to domestic services and retail. On the other hand, large number of high-skilled migrant labours are also attracted towards employment in the city especially from European and Western countries for the following sectors: oil and gas, finance, education as well as investment (Brigitte 2005).

Data of table 4 and figure 2 indicate that the total percentage of the Emirati local people represents about only $11 \%$ of the total population of the city. Arabs and Europeans constitutes small portion, in the other hand most of the city residence are Asians.

Furthermore, Indians compose approximately $30 \%$ of the labour force in Abu Dhabi-ranking first as an exporter of workers. For instance, Indian, Pakistan and Bangladesh form about $50 \%$ of the total foreign worker population. While the remaining population belong to other origins such as Iran, Egypt, Jordan, Sri Lanka, Nepal, Philippines,
Afghanistan and other Asian nationalities. The number of employees from the UK, USA, and Europe have raised up to $3.0 \%$ of the overall labour force; the number of the Emiratis is extremely low composing-about $11 \%$ of the city total population.

Table 4. Percentage of Nationalities of Population of Abu Dhabi City in 2015 *

\begin{tabular}{|c|c|}
\hline Country & $\mathbf{\%}$ \\
\hline Emirati & $11.0 \%$ \\
\hline India & $30.0 \%$ \\
\hline Pakistan & $9.0 \%$ \\
\hline Bangladesh & $7.0 \%$ \\
\hline Philippines & $5.0 \%$ \\
\hline Egypt & $5.0 \%$ \\
\hline Iran & $4.0 \%$ \\
\hline Western Countries & $4.0 \%$ \\
\hline other Arabs & $7.0 \%$ \\
\hline Different Countries & $17.0 \%$ \\
\hline
\end{tabular}

*Source: Abu Dhabi Statistics Centre 2015

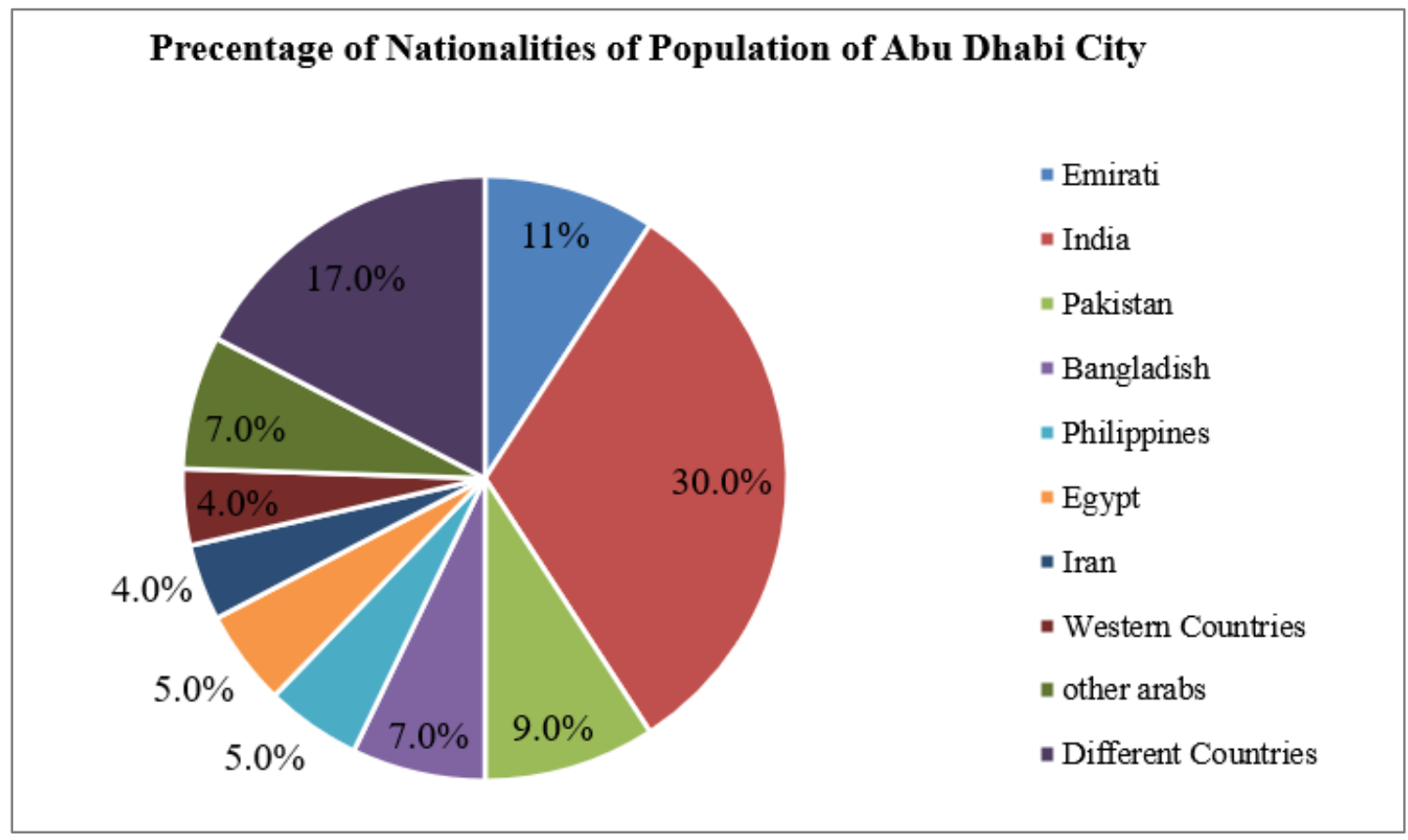

Figure 2. Percentage of Nationalities in Population of Abu Dhabi City 2015 


\section{Consequences of Population Growth on Demographic Characteristics}

The increasing population in Abu Dhabi, United Arab Emirates (UAE) has contributed to the increase in urban sprawl and urbanization, from a humble fishing village in the early 1950s with an area of approximately one square kilometre to a modern metropolis with an area of nearly 761 square kilometres. Abu Dhabi has become a major centre for the inflow of migrants. The increasing number of migrants to Abu Dhabi is creating many positive and negative impacts on Emirati society. This study investigates some effects on the demographic characteristics of Emirati society, particularly, on creating an imbalance of age and sex ratios and unique composition of labour force.

\subsection{Imbalance of Sex Ratio and the Skewed Population Pyramid}

Despite the equal role that both genders play in UAE society, the distribution of males and females has become imbalanced. The sex ratio refers to the ratio of males to females in a society and is measured as the number of males for every 100 females. The sex ratio can contribute to social factors by having an influence on demographic groups, marriage ratios, and population growth. It can also affect death and birth rates as well as migration trends to and from an area. Migrant workers constitute approximately $90 \%$ of the population in Abu Dhabi, the majority of whom are male. For instance, in 2005 the sex ratio of the country was 216 males per 100 females. Moreover, for the past three censuses, the ratio has been greater than 200 males per 100 females. The ratio is even higher among migrants; about 255 males and 267 males per 100 females in 1995 and 2005 respectively.

According to the data in Table 5, the sex ratio in $\mathrm{Abu}$ Dhabi is one of the highest among all urban centres in the UAE, reaching 265 males per 100 females and 317 males per 100 females for non-citizens in 2015 . The sex ratio also differs in urban and suburban areas with the latter being higher. For example, the sex ratio is higher in poor industrial areas such as Al Musaffah (greater than 600 males per 100 female) compared to 105 males per 100 females in residential areas that are inhabited by Emiratis, such as the suburbs of Shamhka and Shahama. The sex ratio is also high among Asian workers from India, Bangladesh, Pakistan, and Afghanistan, especially those who work in construction and other arduous physical work. The rate declines slightly for servants and housekeepers from the Philippines, Indonesia, Ethiopia, and Sri Lanka. The imbalance is more obvious in the 30-39 age group where the sex ratio is 307 males per 100 females.

Accordingly, migration has a remarkable influence on the age and sex structure of the Abu Dhabi population leading to a skewed population pyramid as illustrated in Figure 3. Many guest workers in the age group 20-64, most of whom are 'blue-collar' workers, cannot afford to live in Abu Dhabi due to a high cost of living. After the age of 65, guest workers that have spent their entire working life in Abu Dhabi return to their home countries at the age of retirement.

Due to high birth rates and low death rates, the population pyramid of citizens in Figure 3 has a wide base. This implies a high fertility rate and declining death rate. The population pyramid of migrants shows an increase in the number of young people of working age, specifically males. The figure also shows a significant decrease in the number of people in the older age groups as young workers withdraw from the labour market. The age structure of $\mathrm{Abu}$ Dhabi's population is affected by the inflow of guest workers, as indicated in Table 6. Although Abu Dhabi has a large proportion of people in the 15-64 age group (greater than $82 \%$ ), the number of people in the $65+$ age group is significantly smaller (1\%). In addition, the small percentage of young people in Abu Dhabi (16.7\%) is the result of a declining birth rate (only 10 per thousand) among guest workers

The data in Table 6 indicates that the characteristics of citizens differ from non-citizens, where $38.5 \%$ of citizens are in the young age group (below 15 years), due to high fertility, while the proportion of elderly persons $(65+)$ is very low (2.3\%). Abu Dhabi has an expansive population pyramid shape with a broad base and narrow top reflecting high fertility for citizens, and a skewed shape for non-citizen guest workers. With the onset of the demographic transition, the age structure of Abu Dhabi began to undergo change. A decline in the death rate, as well as a decline in the birth rate from 32 per thousand in 1985 to less than 14 per thousand in 2015, occurred because of significant development.

Table 5. Sex Ratio of Abu Dhabi City in 2015. (Number of Males per 100 Females) *

\begin{tabular}{|c|c|c|c|c|c|c|}
\hline \multirow{2}{*}{ Area } & \multicolumn{2}{|c|}{$\mathbf{1 9 9 5}$} & \multicolumn{2}{|c|}{$\mathbf{2 0 0 5}$} & \multicolumn{2}{c|}{$\mathbf{2 0 1 5}$} \\
\cline { 2 - 7 } & Non-Citizens & Total & Non-Citizens & Total & Non-Citizens & Total \\
\hline Abu Dhabi & 259 & 205 & 294 & 223 & 265 \\
\hline UAE & 249 & 185 & 255 & 200 & 267 \\
\hline
\end{tabular}

*Source: Abu Dhabi Statistic Centre, Population and Vital Statistics (www.scad,gov.abudhabi.ae).

Table 6. Population Distribution of Broad Age Groups in Abu Dhabi 2015 *

\begin{tabular}{|c|c|c|c|}
\hline Age Groups & Young (0-14) & Adults (15-64) & Old (65+) \\
\hline Total & 16.7 & 82.3 & 1.0 \\
\hline Non-citizens & 11.4 & 88 & 0.6 \\
\hline Citizens & 38.5 & 59.2 & 2.3 \\
\hline
\end{tabular}

*Source: Abu Dhabi Statistics Centre, Population and Vital Statistics. (www.scad,gov.abudhabi.ae) 

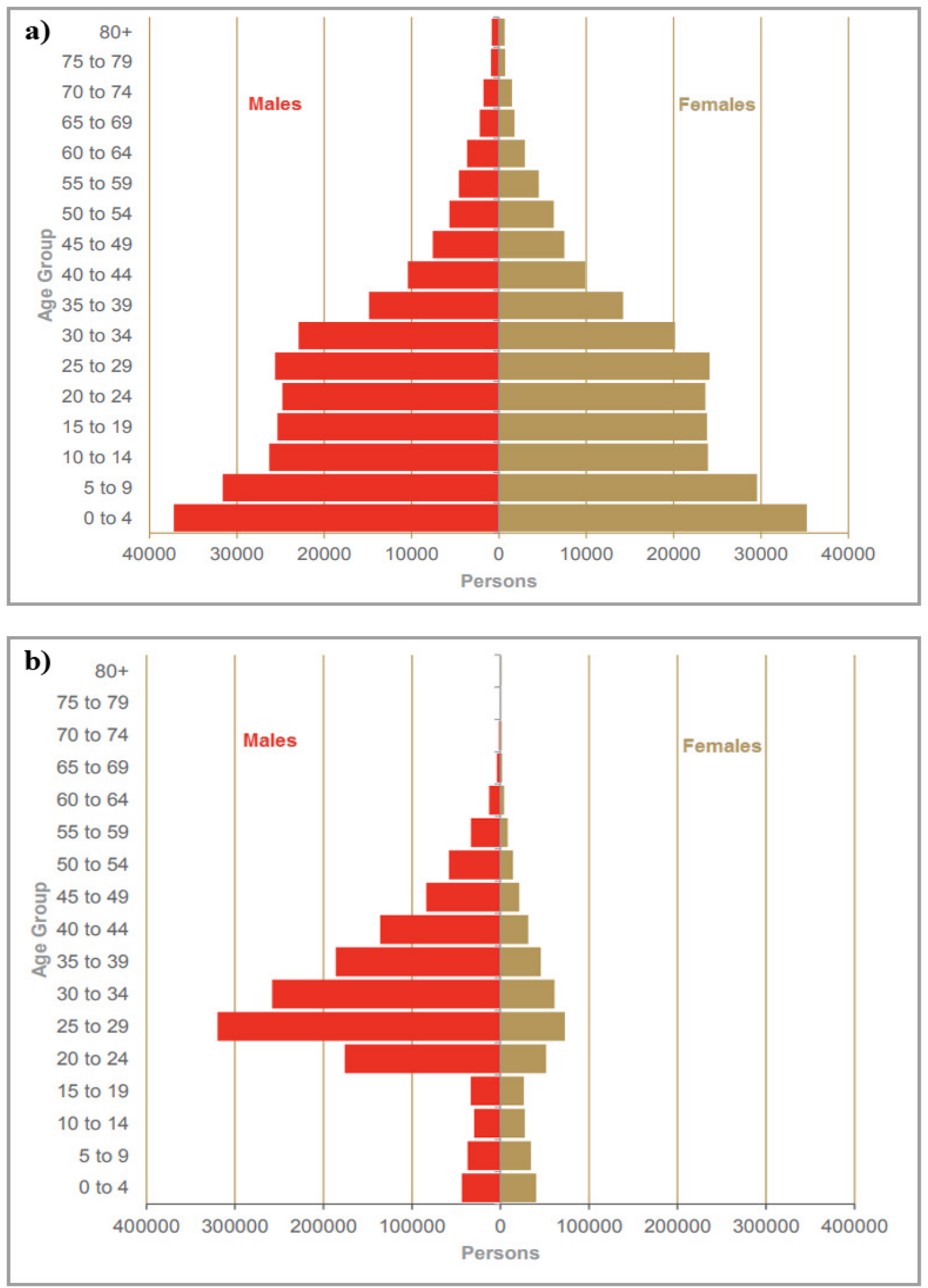

(Source: www.scad,gov.abudhabi.ae)

Figure 3. Age and Sex Population Pyramids of Abu Dhabi, 2015. (a) citizens (b) non-citizens 


\subsection{The Unique Composition of Abu Dhabi's Labour Force}

The labour force in Abu Dhabi is high, constituting more than $83 \%$ of the total population. However, the percentage of women in the labour force is low compared to many other counties in the world. Only one-fifth of working-age women participate in the labour force. In addition, the unemployment rate in Abu Dhabi is low, but the cost of living is high. The current unemployment rate is $3.7 \%$, which is low compared with many other urban centres that have double digits.

The labor market in the United Arab Emirates is divided into private and public sector directly representing expatriates guest workers and locals. Foreigners are over-represented in the private sector, while the nationals hold the jobs in the much more regulated public sector. Expatriate men do nearly all material production, while almost all domestic work is done by expatriate females (Massey., 1998). The working conditions differ drastically between the public and the private sector. Employees of the governmental sector get more benefits; they have fewer working hours, a minimum salary, more holidays and better pension system. In the private sector, there is no regulation concerning minimum salary, there are more working hours, less holidays and less benefits (Kapiszewski, A.,2001). In 2018, for employed citizens about $87 \%$ worked in the governmental sector and only 5.5 percent were employed in the private sector (Abu Dhabi Statistics Centre (2018).). Although, this number is misleading. Many nationals have a second job in the private sector and/or are involved in the private sector as joint owners or sponsors which give them a substantial income.

The rapid growth in Abu Dhabi's labour force was accompanied by a similar, but slightly slower, growth in population. The labour force increased from approximately 90,000 in 1975 to 400,000 in 2015 (6.2\% annual growth rate), which exceeded that of the population (5.3\% annual growth rate) by nearly $1 \%$. Moreover, during the period from 1995 to 2015, the difference between the labour force and population growth rates widened to approximately $2 \%$, which can be explained by the high and rapid economic growth, especially in sectors that require large numbers of unskilled workers such as construction and domestic work. While the citizen population continued to increase, the growth rate was not as fast as the growth rate of the guest worker population. The citizen labour force grew by $2.8 \%$ annually, while guest worker growth rate reached $16 \%$ annually. The percentage of guest workers participating in the labour force increased from $85 \%$ in 1975 to $91 \%$ in 2015. By contrast, the percentage of citizens participating in the labour force decreased from $9 \%$ in 1975 to $7 \%$ in 2015.

The increase in the number of the expatriate guest workers has been accompanied by several challenges, particularly managing employment opportunities. The country aimed to find a balance between attracting the labour needed to build the economy while maintaining high employment rates among its national population via so-called Emiratization. The unemployment rates for nationals have significantly increased from $5.7 \%$ for males and $7.1 \%$ for females in 1995 to $13.3 \%$ for males and $18 \%$ for females in 2015. The main reason for this is that most nationals prefer to work in government sector like administrative jobs. In addition, the unemployment rate tends to continue increasing for many reasons such as the increasing number of university graduates, training which does not meet labour market demands and a demanding work environment in the private sector with respect to working hours and close performance measurements. In addition, natives do not accept many low-skilled jobs with low salaries because of tradition or lack of social appeal.

The composition of the labour force takes into consideration other demographic factors such as age, gender, nationality, education, and specialized skill. Regarding gender, the dominance of males in the labour force of Abu Dhabi has been widening over the years. In 1995 , females in the labour force comprised $11.5 \%$ of the total labour force. After ten years, this share had slightly increased to $11.6 \%$. As for nationality, the major increase in the females' share of the labour force has been among nationals, increasing from $16.4 \%$ in 1995 to $27.8 \%$ in 2015 . This is due to an increasing number of university graduates and results in the decrease of female expatriates from $11.2 \%$ in 1995 to $10.9 \%$ in 2015 .

Expatriates constitute the major share of the labour force. In 2015 , nationals represented only $4.3 \%$ of the labour force, a decrease from $6 \%$ in 1995 . The share of national females in the labour force increased from $8.5 \%$ in 1995 to $10.3 \%$ in 2015 , while the share of national males decreased by $2.2 \%$, reaching only $3.5 \%$ in 2016. (Abu Dhabi Statistics Centre (2016).).

In 2009, the public sector (federal and local) employed $90 \%$ of the working nationals and $10 \%$ of the foreign workers. Another $15 \%$ of foreign workers worked in the domestic sector, but the majority (65\%) were in the private sector. Emiratis comprised $60 \%$ of the total workforce in the public sector in 2015 , but only $0.5 \%$ of the private sector's workforce. Due to the demographic imbalance characterizing the country, and especially its workforce, foreign workers indeed dominate numerically at every occupational level. A 2008 survey indicated that foreign workers made up $89 \%$ of all managers and $99 \%$ of those in unskilled positions. In the UAE, unlike in other GCC states where foreign workers are mostly clustered in low- and semi-skilled occupations, foreign workers are employed in low- to high-skilled occupations. (Brigitte, S., (2005).

Concerning education, approximately $57.5 \%$ of the non-Emirati labour force held below secondary level education in 2005 (a level like that of Emiratis). The share of people holding university degrees was higher among foreign workers $(15 \%)$ than Emiratis $(11.8 \%)$. The 
proportion of nationals with high educational attainment has been increasing over time due to the high level of economic growth in the UAE since the 2000s. The share of nationals with tertiary education has risen from $25 \%$ in 1995 to $35 \%$ in 2005 . The percentage of nationals with basic education (primary school or less) has decreased by $19 \%$ during the period from 1995 to 2005 , reaching $13 \%$. The pool of skilled expatriates has also risen over the same period but on a smaller scale. The percentage of all Emirati labour force increased from $66 \%$ in 1975 to $74 \%$ in 2015 . The percentage of non-national labour force with tertiary education increased from $18 \%$ in 1995 to $20 \%$ in 2015 .

The age structure of the national labour force did not change significantly during the period from 1995 to 2015. The age group 25-29 still constitutes the largest share for both genders $(8.1 \%$ for females and $13.4 \%$ for males in 2015). However, for all age groups, the percentage of Emirati women in the labour force has increased from $2.6 \%$ in 1975 to $27 \%$ in 2015 . Female expatriates increased from $17.7 \%$ to $54 \%$ during the same period.

According to the Abu Dhabi Statistical Year Book (2018), 30\% of Abu Dhabi's labour force is employed in the construction industry, $25 \%$ in administration, defence, and compulsory social security, and $9 \%$ in agriculture, fishing, and mining (see Figure 4).

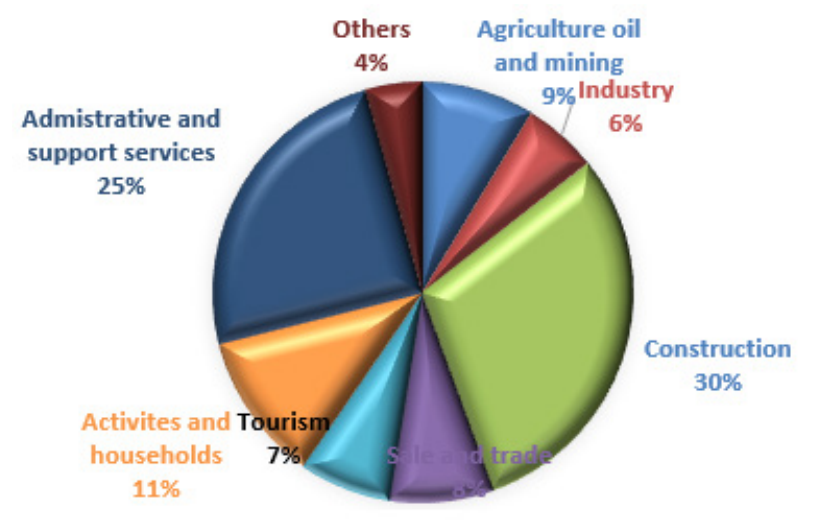

Figure 4. Employees by Economic Activity in Abu Dhabi 2018

There are some differences in the composition of the labour force between citizens and foreigners. In addition, Western nationalities are overwhelmed in the upper echelons of occupations. By contrast, $61 \%$ of Asians are 'blue-collar' workers and $15 \%$ perform managerial and professional occupations.

Emirati nationals were also mostly concentrated in public administration, defence, and social security, which consisted of $65.7 \%$ males. Females were concentrated in education, health, and social work; accommodation and food services; and public administration, defence, and social security. As for non-Emiratis, $22 \%$ worked in retail, trade, and tourism, 30\% in construction, $26 \%$ in domestic services, and $9 \%$ in manufacturing and transport. Real estate and business, as well as public administration, employed $7 \%$ of foreign labourers. This further highlights the scale of expatriates' participation in the UAE economy both in the private and public sectors, as well as the diversity of the non-national population, in terms of skills and areas of specialisation. (De Bel-Air, F., 2015):

Data of the employed population by educational attainment shows that $36 \%$ of employees have less than primary and primary levels of education, followed by $25.2 \%$ with secondary level of education, and $17.5 \%$ with a bachelor's degree. $44 \%$ of male Emirati employees have a secondary school certificate, followed by 28.45 that have a bachelor's degree. $45.6 \%$ of Emirati female employees have a bachelor's degree, followed by $39.3 \%$ that have a secondary school certificate. $38 \%$ of the guest workers have less than primary or primary education, followed by $16 \%$ that have a bachelor's degree. Most of the male guest workers $(40 \%)$ have no certificates and $14.5 \%$ of them have a bachelor's degree. By contrast, $28.3 \%$ of the female foreign workers have a bachelor's degree, followed by $28.3 \%$ that have a secondary certificate.

As mentioned earlier, the unemployment rates for nationals have significantly increased from $5.7 \%$ for males and $7.1 \%$ females in 1995 to $13.3 \%$ for males and $18 \%$ for females in 2015. The main reasons for the existence of unemployment among nationals is the segmentation of the labour market according to sector, whereby locals are concentrated in the public sector and expatriates in the private sector. (Al-Jenaibi, 2015) The wage differential between the two sectors and the better benefits offered in government occupations encourages national workers to find employment in the public sector. The rise in the labour force participation rates of females has also been a contributing factor to the unemployment problem. (Nelson., C.,2004)

\section{Conclusions}

Abu Dhabi's population increased sharply from nearly 100,000 in 1975 to more than 1,25 million in 2018. The high population growth has been achieved by attracting large numbers of foreign guest workers from many countries mostly from Asian. The inflow of migrants has played a significant role in changing the population size, age, sex structure, nationality, and economic activities. Most of the foreign workers are middle-aged males who come to meet the requirements of the labour market. There are many consequences that followed the rapid population growth of the city as the decline of the percentage of Emirati people to less than 12 percent. The majority of Abu Dhabi inhabitants are adult males aged 25-60, which leads to the abnormalities in the population pyramid and the unbalanced sex ratio, which exceeds 260 males for every 100 females. There is a clear difference in the composition of the labour force between Emirati citizens who are concentrated in the governmental sectors and the guest workers working in the private sector. The educational 
status of the Emirati's labour force shows some differences between males $(50 \%$ have secondary school certificates followed by approximately $30 \%$ with Bachelor degrees). By contrast, about $46 \%$ of Emirati females have a Bachelor certificate and $40 \%$ have secondary school certificates. Most of the guest workers $(40 \%)$ have no certificate and only $14 \%$ have Bachelor degrees. Finally, the unemployment ratio is higher among Emiratis than foreigners.

\section{REFERENCES}

[1] Abu Dhabi Statistics Centre (2018). Statistical Yearbook of Abu Dhabi 2018. Retrieved 20 May 2016 from https://www.scad.gov.abudhabi/Release\%20Documents/SY B_2018_EN_9Sep.pdf

[2] Abu Dhabi Statistics Centre, Labour force Survey, 2013. https://www.scad.gov.ae/MethodologyDocumentLib/Labou r\%20Force $\% 20$ Survey $\% 202013 \% 20-\% 20$ Metho\%20-\%20 En.pdf

[3] Abu Dhabi Statistics Centre (2016). Key indicators. Retrieved 27 September 2016 from https://www.scad.ae/en/ pages/default.aspx.

[4] Al-Jenaibi, B., (2015): The Needs and Priorities of Women in the UAE: Identifying Struggles and Enhancing Satisfaction of Employment, Education, Health Care, and Rights https://doi.org/10.1177/2347798915601590

[5] Brigitte., (2005) Labour Migration in the United Arab Emirates, master Thesis, Malmo University https://pdfs.semanticscholar.org/6d20/a33a49ec59c5dbc97a 2eccbfe332351e0a5c.pdf

[6] De Bel-Air, Françoise (2015): Demography, Migration, and the Labour Market in the UAE. Gulf labour markets and migration, No. 7.

[7] Elessawy, F. (2014): Living in the Move: Impact of Guest workers on Population Characteristics of the United Arab Emirates, The Arab World Geographer, Vol. 17, Issue 1, pp. 2-23.

[8] Elessawy, F. (2017): The Boom: Population and Urban Growth of Dubai City, Horizons in Humanities and Social Sciences, 2(2): 26-41.

[9] Forstenlechner, I. (2010) Unemployment in the Gulf, Middle East PolicyXV11,no.2 pp. $38-51$

[10] Froilan T. Jr., Malit, and Ali Al Youha. "Labour Migration in the United Arab Emirates: Challenges and Responses," Migration Information Source, September 18, 2013, http://www.migrationpolicy.org/article/labormigration-unit ed-arab-emirates-challenges-and-responses.

[11] Gallacher, D., (2009). The Emirati Workforce. Abu Dhabi: Zayed University.

[12] Kapiszewski, A. (2001). Nationals and Expatriates. Population and Labor Dilemmas of the Gulf Cooperation council States, Ithaca Press, Reading.

[13] Massey, D., et al (1998) Worlds in Motion, Understanding International Migration at the End of Millennium, Clarendon Press, Oxford.

[14] Naufal, George. "The Economics of Migration in the Gulf Cooperation Council Countries." In Handbook of the Economics of International Migration, Volume 1B, eds. Barry Chiswick and Paul Miller. Amsterdam, Boston, etc.: North Holland / Elsevier, 2014.

[15] Nelson., C., (2004), UAE National Women at Work in the Private Sector; Conditions and Constrains, Centre of labour Force Research \& Information (CLMRI), Ministry of Information, Dubai. http://citeseerx.ist.psu.edu/viewdoc/do wnload?doi=10.1.1.515.9540\&rep=rep1\&type $=$ pdf 